\title{
The Public Dilemma of Rural Public Cultural Space and Its Countermeasure
}

\author{
Du Yu ${ }^{1, \mathrm{a}}$, Qiyuan $\mathrm{Li}^{2, \mathrm{~b}^{*}}$ \\ ${ }^{1}$ School of Management, China West Normal University, Nanchong,Sichuan, China \\ ${ }^{2}$ School of Management, China West Normal University, Nanchong,Sichuan,China \\ aDY272005016@163.com \\ b*191895426@qq.com
}

\begin{abstract}
Cultural revitalization is an important part of rural revitalization. Rural public cultural space is of great importance of rural culture and is the main venue for rural cultural activities. With the development of industrialization and urbanization,the original pattern of rural public cultural space has been gradually destroyed. It is challenged by public dilemma such as lack of people,the shrinking of space,loss of public interest,disorder of culture,which hinders the overall development of rural areas and the implementation of rural revitalization strategies. In response to this dilemma,we should respect the needs of villagers and strengthen the construction of rural culture.
\end{abstract}

Keywords: rural public cultural space; publicity; dilemma

\section{乡村公共文化空间的公共性困境及对策}

杜宇 ${ }^{1, a}$ 李其原 ${ }^{2, b *}$

${ }^{1}$ 西华师范大学管理学院, 南充, 四川, 中国

2 西华师范大学管理学院, 南充, 四川, 中国

${ }^{a}$ DY272005016@163.com

b*191895426@qq.com

\section{摘要}

文化振兴是乡村振兴的重要环节。乡村公共文化空间是乡村文化的重要组成部分，是进行乡村文化活 动的主要场所。随着工业化、城镇化的不断推进, 乡村公共文化空间的原有格局被逐渐破坏, 面临着 建设主体缺席、空间萎缩、公共利益流失、文化失调等公共性困境，阻碍了乡村的整体发展和乡村振 兴战略的实施。应对公共性危机应该尊重人的需求，加强乡村文化建设。

关键词：乡村公共文化空间；公共性；困境

\section{1. 前言}

文化是一个民族的灵魂,中华民族的伟大复兴离不 开文化的复兴。乡村公共文化空间, 首先是人们的日常 生活空间, 其次也是乡村文化活动的载体。然而伴随社 会的高度发展, 乡村公共空间出现了一系列公共性危 机，造成了乡村治理的困境。

\section{2. 关于乡村公共文化空间}

\section{1. 乡村公共文化空间内涵}

关于乡村公共文化空间, 学者高春凤指出, 乡村公
共文化空间是农民生产和生活的物理场域 [1]。学者陈波、 李婷婷认为, 农村公共文化空间是农村社区内的人们可 以自由进入并利用公共文化资源进行文化生活的公共 场所, 以及人们能够参与其中享受文化福利的公共文化 活动 [2]。学者张琳等将乡村公共文化空间定义为, 乡村 社区内部公共性的、农民可以自由进入并进行文化生活 的空间 ${ }^{[3]}$ 。

\section{2. 乡村公共文化空间的功能及发展}

学者马永强指出乡村公共空间具有物理功能和文 化功能 ${ }^{[4]}$ 。学者张琳等认为, 乡村文化空间是人际交往 的主要空间以及文化传承的主要载体 [3]。学者陈波、李 婷婷认为, 农村公共文化空间是农村居民参与文化生活 的载体 ${ }^{[2]}$ 。

当前的乡村公共空间普遍存在着供给短缺、功能弱 
化、公共性流失、过度市场化等问题 ${ }^{[5]}$, 学者们分别从 不同角度提出了重构乡村文化公共空间的路径。例如, 学者高春凤认为, 可以借助乡村公共文化空间的叙事性 阐释留住乡愁 ${ }^{[1]}$ 。学者陈波、李婷婷提出了再造农村公 共文化空间模式: 池塘群落型、设施助推型、信仰聚落 型、活动召集型 ${ }^{[2]}$ 。

就既有的研究来看, 学者们的侧重分析点不同, 所 以各自的理解也不同。针对乡村公共文化空间的问题, 学者们大都从外部因素进行分析, 而较少研究内生性原 因。本文重在从公共性的视角去分析乡村公共文化空 间, 并试图提出缓解乡村公共文化空间公共性危机的对 策。

\section{3. 乡村公共文化空间的公共性}

学者张诚等认为, 乡村公共空间公共性, 是指基于 公共需求产生的乡村公共空间, 以自身的资源为基础, 以公共活动为载体, 以平等、多元等为核心理念, 以实 现公共利益为价值追求的过程中所体现出的一种社会 属性 ${ }^{[6]}$ 。本文认为, 乡村公共文化空间的公共性, 是指 乡村内的公共文化空间, 如图书馆、学校、文化广场、 农家书屋等, 基于自身的文化场域和公共资源, 通过公 共活动将人们联系在一起, 推动私性文化向公性文化的 转变过程中表现出来的一种社会性质。

\section{3. 乡村公共文化空间的重要性}

发展乡村公共文化空间与乡村振兴战略是高度一 致的关系。首先, 发展乡村公共文化空间的目的是振兴 乡村文化, 而文化振兴作为乡村振兴的组成部分, 是乡 村振兴的精神基础, 也是乡村振兴的重要目标, 在此方 向上, 二者目标相同。发展乡村公共文化空间, 促进乡 村文化大繁荣, 是为了达到振兴乡村文化的目的。乡村 文化振兴是乡村振兴战略的铸魂工程, 是实现乡村可持 续发展的内生动力。其次, 发展乡村公共文化空间需要 培养文明乡风, 而实现乡风文明也是乡村振兴战略的要 求, 二者要求相同。进行乡风文明建设, 有利于乡村公 共空间的保护与发展, 继而全面实现乡村振兴。最后, 发展乡村公共文化空间的本质上是为了实现乡村的健 康、可持续发展, 乡村振兴战略的实质亦是如此, 二者 本质相同。城市与农村的二元结构、城镇化进而导致的 乡村空心化等问题给乡村文化发展带来负面影响。二者 的本质就是要解决乡村的持续发展问题。

\section{4. 乡村公共文化空间的发展现状}

乡村公共文化空间在乡村治理中扮演重要角色, 是 推进乡村治理的内在动力。然而在乡村社会的转型期, 乡村公共文化空间的发展现状却不如人意, 已满足不了 农民多样化的、多层次的精神文化需求。

\section{表 1 乡村基础文化设施状况}

单位: \%

\begin{tabular}{|c|c|c|c|c|c|}
\hline & 全国 & $\begin{array}{l}\text { 东 部 } \\
\text { 地区 }\end{array}$ & $\begin{array}{l}\text { 中 部 } \\
\text { 地区 }\end{array}$ & $\begin{array}{l}\text { 西 部 } \\
\text { 地区 }\end{array}$ & $\begin{array}{l}\text { 东 北 } \\
\text { 地区 }\end{array}$ \\
\hline $\begin{array}{l}\text { 有 图 书 } \\
\text { 馆、文化 } \\
\text { 站的乡镇 }\end{array}$ & 96.8 & 96.2 & 98 & 96.6 & 95.2 \\
\hline $\begin{array}{l}\text { 有剧场、 } \\
\text { 影剧院的 } \\
\text { 乡镇 }\end{array}$ & 11.9 & 18.5 & 14.4 & 7.9 & 5.9 \\
\hline $\begin{array}{l}\text { 有公园及 } \\
\text { 休闲健身 } \\
\text { 广场的乡 } \\
\text { 镇 }\end{array}$ & 70.6 & 83.2 & 73.9 & 59.4 & 84 \\
\hline $\begin{array}{l}\text { 有体育健 } \\
\text { 身场所的 } \\
\text { 村 }\end{array}$ & 59.2 & 72.2 & 55.5 & 46 & 62.8 \\
\hline $\begin{array}{l}\text { 有农民业 } \\
\text { 余文化组 } \\
\text { 织的村 }\end{array}$ & 41.3 & 44.4 & 40.8 & 36.7 & 47. 1 \\
\hline
\end{tabular}

注: 本表数据来源于第三次全国农业普查主要数据公报 (第三号)

据表 1 可知，截止 2016 年末，全国 96.8\%的乡镇有 图书馆、文化站， $11.9 \%$ 的乡镇有剧场、影剧院，70.6\% 的乡镇有公园及休闲健身广场，59.2\%的村有体育健身 场所，41.3\%的村有农民业余文化组织。从表 1 还可以 看出以下几个问题: 第一, 全国有剧场、影剧院的乡镇 数量还较少。第二, 发展不均衡, 地区差异较大。东部 地区有图书馆、文化站的乡镇数量略低于全国水平; 中 部地区有体育健身场所的村和有农民业余文化组织的 乡镇数量低于全国水平; 而西部地区均未达到全国水 平; 东北地区有图书馆、文化站的乡镇和有剧场、影剧 院的乡镇数量低于全国水平。第三, 最高值和最低值差 异较大。公共文化场所覆盖率最高的是, 中部地区有图 书馆、文化站的乡镇覆盖率达到 $98 \%$, 但覆盖率最低的 是东北地区, 有剧场、影剧院的乡镇只有 $5.9 \%$ 。学校、 图书馆、剧场、公园、体育健身场所都是乡村公共文化 空间，为村民提供了公共场所和公共产品，促进了地区 特色文化的传播, 但私性文化的兴起对公共文化造成了 一定的冲击, 削弱了公共文化的效果。综合目前的发展 状况来看, 乡村的文化设施与文化场所有了一定的发 展, 最大的问题应该是区域发展的不协调。

\section{表 2 乡村人口状况}

\begin{tabular}{|c|c|c|c|c|c|}
\hline 年份 & $\begin{array}{l}\text { 全国总 } \\
\text { 人口数 } \\
\text { 量 (/万 } \\
\text { 人) }\end{array}$ & $\begin{array}{l}\text { 城 镇人 } \\
\text { 口 数 量 } \\
\text { ( / / 万 } \\
\text { 人) }\end{array}$ & $\begin{array}{l}\text { 乡 村 } \\
\text { 人 口 } \\
\text { 数 量 } \\
\text { (/万 } \\
\text { 人) }\end{array}$ & $\begin{array}{l}\text { 城 镇 } \\
\text { 化率 } \\
(/ \%)\end{array}$ & $\begin{array}{l}\text { 农民工 } \\
\text { 总量 } \\
\text { ( / 万 } \\
\text { 人) }\end{array}$ \\
\hline
\end{tabular}




\begin{tabular}{|l|c|c|c|c|c|}
\hline 2014 & 136782 & 74916 & 61866 & 54.77 & 27395 \\
\hline 2015 & 137462 & 77116 & 60346 & 56.10 & 27747 \\
\hline 2016 & 138271 & 79298 & 58973 & 57.35 & 28171 \\
\hline 2017 & 139008 & 81347 & 57661 & 58.52 & 28652 \\
\hline 2018 & 139538 & 83137 & 56401 & 59.58 & 28836 \\
& & & & & \\
\hline
\end{tabular}

注: 本表数据来源于 2014-2018 年国民经济和社会发展 统计公报

根据表 2 显示，从 2014 年至 2018 年，全国总人口 数量共增加了 2756 万人, 其中乡村人口数量减少了 5465 万, 而城镇人口数量一直上升, 增加了 8222 万; 城镇 化率由 54.77\%增长到 59.58\%; 农民工总量也呈稳步上 升趋势。究其原因, 主要是大量农村居民被城市的繁荣 与现代化所吸引，加之农村地理位置偏僻、条件艰苦、 经济水平不高, 于是放弃农村转而进入城市寻求生存与 发展。许多农民进入城市后, 享受到了城市便捷的交通、 优质的教育资源、健全的医疗设施，便努力打工赚取足 够的积蓄以求在城市定居。越来越多的人口从农村流向 城市，导致农村人口空心化、老龄化。这也就导致了参 与乡村公共文化活动主体的缺失, 使得乡村特色文化得 不到传承和发扬, 乡村公共文化空间无人建设。

\section{5. 乡村公共文化空间的公共性困境}

乡村振兴战略给乡村公共文化空间带来了新的发 展机遇, 然而其发展背后却隐藏着深深的失落与危机。 乡村公共文化空间遭遇的公共性困境, 如建设主体缺 席、文化空间萎缩等, 都不利于乡村社会的和谐发展。

\section{1. 乡村公共文化空间建设主体缺席}

人的参与是公共性的重要特征, 建设乡村公共文化 空间需要村民的积极参与。由前表可知, 目前, 农村居 民大量涌入城市, 城镇化率逐年上升, 农村人口空心化、 老龄化现象严重。青壮年本该是参与公共文化活动的主 力军, 最后却成为农民工大军流入城市。而留在农村的 老人、儿童和妇女根本无暇关注乡村公共文化空间的建 设, 也无力参与公共文化活动。其次, 由于电子化、网 络化的发展, 私性文化的兴起, 影响了村民参与公共文 化活动的积极性。缺少了人的参与, 公共文化活动显得 苍白无力。最后, 由于政府对公共文化空间发展的干预, 村民的参与受到诸多限制，致使村民们的公共意志得不 到体现。

\section{2. 乡村公共文化空间萎缩，社会功能退化}

在乡村社会的转型期，乡村公共空间也由原来的田 间地头转变为集市、商店、大树下、水井旁等。乡村公 共空间原本是村民日常进出交流的场所，人气兴旺。而 由于社会的变迁、市场经济的发展，村民的生活发生了 翻天覆地的改变。以前大家都有串门聊天的习惯, 但随 着电视、网络的普及, 人们更倾向于在家看电视、玩手 机。还有空调的出现, 带来的凉意也打败了大树底下的 荫凉。一些地方特色的习俗, 如开灯会、舞狮等, 也逐 渐淡出了人们的生活。同时, 由于乡村人口的减少, 公 共文化活动的也逐渐减少, 乡村公共文化空间的社会功 能在慢慢退化。

\section{3. 公共利益的流失}

公共空间的公共性都要以公共利益为纽带。公共利 益与个人利益既相互区别又紧密联系, 公共利益因具有 公共性而有别于个人利益, 同时公共利益又是个人利益 的共同体。在传统社会, 公共利益包括家族利益、公社 利益等, 公共利益与私人利益是共存的关系。然而, 随 着市场经济的发展和工业化、城市化的推进，人们的私 性文化被激发，更多的关注自己的个人利益，对农村社 会的公共利益表现得越来越冷漠。农村社会的公共利益 不断减少, 一些公共空间无人建设, 丧失了其原有的公 共性。

\section{4. 农村公共文化的失调}

农村社会的道德规范, 是由于血缘和地缘关系的促 进, 由小范围的约定俗成而发展成共同的社会意识和价 值取向。这种社会意识, 能够促进农村社会的团结, 维 护农村社会的公共性。由上表可知, 我国的城市化率逐 年升高, 农村逐渐变得萧条。在农村人口流向城市的过 程中，传统农村的封闭格局也在被打破，农村的村庄秩 序、价值观念等不断受到冲击, 在此过程中出现了一些 不适应的情况, 导致农村文化的失调。文化的失调, 导 致农村社会出现了许多问题，如人心冷漠、道德崩坏等。 价值观的歪曲直接影响了集体行动和公共精神, 导致公 共性危机。

\section{5. 公共文化空间的发展偏离人的需求}

人的需求是公共性的重要体现，乡村公共文化空间 的发展如果没有考虑人的需求, 其公共性也得不到体 现。目前, 受到城市化的影响, 乡村公共文化空间的建 设大多数以城市为模板, 把建设城市的那一套方法直接 照搬过来, 建设许多不符合农村特征的公园和广场, 这 反而破坏了乡村原有的特色。其次，各种公共文化空间 的建设成为政府绩效考核的重要指标, 各种权力都在介 入乡村公共文化空间的建设和发展中，使得其发展逐渐 
政治化, 体现了政府意志, 而非人的需求。最后, 随着 市场的力量也渗透到乡村公共文化空间的发展之中, 成 为建设主体。而市场化的发展, 也扰乱了原本的农村社 会秩序。

\section{6. 乡村公共文化空间公共性危机的应对策略}

乡村公共文化空间的重要性决定了它在乡村发展 中的重要地位。乡村公共文化空间的发展应该借助乡村 振兴战略政策的优势, 满足村民需求, 建设属于村民的、 具有乡土特色的文化空间。

\section{1 加快农村基础设施建设}

加快农村基础设施建设，有利于推动农村现代化， 吸引人口回流。建设乡村公共文化空间的主体涌入城 市，原因之一是城乡公共服务的严重不均等。长期以来， 城乡经济发展严重失调, 农村缺少发展机会, 在教育、 文化、卫生、养老等事业方面落后。要吸引人口回流， 就要加强农村基础设施建设, 推动城乡一体化发展。首 先, 完善农村基础教育体系, 促进城乡教育资源共享。 合理规划学校布局, 合理分配教师资源。其次, 促进农 村公共文化事业发展。加强农村文化设施建设, 加大公 共财政投入, 促进农村文化事业繁荣发展。然后, 完善 农村公共卫生和医疗服务。大力发展农村公共卫生事 业, 优化农村医疗服务, 推动优质医疗资源下沉。最后, 发展农村养老事业。政府进行适当补贴, 鼓励农村设立 养老机构，吸引社会资本力量的投入。

\section{2. 加强公共文化空间建设，创新公共文化活 动形式}

由于乡村公共空间的萎缩, 在现有状况下, 要加强 公共文化空间建设，推进基础文化设施的建设。乡镇的 财政状况难以支持文化空间的建设工作，因而政府应该 进行协调安排，设立专项资金以支持公共图书馆、文化 广场等的建设。首先, 加大人力、财力、物力的投入。 通过多种方式, 汇聚各方力量, 整合资源, 补上资金短 板。其次, 创新公共文化活动形式, 吸引更多人的参与。 从村民的实际需求出发, 提供更加贴近人民群众需求的 公共文化。改变由政府包揽的单一形式, 鼓励其他多方 力量的进入，保证公共文化服务的质量。

\section{3. 培育乡村社会资本}

乡村社会资本是推动农村公共文化发展的内生性 要素, 可以为农村公共文化空间的建设和发展提供持续 性动力。首先, 农村社会资本要正确对待地方优秀传统 文化, 保持敬畏的态度, 同时进行深度了解与挖掘, 对 于其中有地方特色的精华部分进行保护, 其他不符合社
会价值观的文化, 要进行改造, 使其重生。在继承传统 文化的基础之上，融入现代化元素，让其得到更好的发 展。其次, 对于一些约定俗成的乡规民约, 应该发挥其 积极作用, 规范农村社会的行为, 维护农村社会的稳定 秩序。最后, 沿袭村庄流传下来的传统家风家谱、历史 故事, 撰写村史存志, 构建村庄集体的文化记忆, 保护 并发展村庄文化空间，留住乡愁。

\section{4. 加强乡村文化建设}

当前乡村文化的失调是导致乡村文化空间公共性 危机的重要因素。加强乡村文化建设要从以下几个方面 进行考虑: 首先, 提高农村组织能力。转型中的农村社 会, 组织能力降低, 大家都以自己的事务为先, 不想参 与公共活动。提高农村组织能力要积极动员村民参与公 共文化活动, 使村民的主体能动性得到发挥。其次, 抵 制拜金主义、消费主义等奢靡享乐之风。农村向现代化 发展的过程中的不适应, 表现之一就是奢靡享乐之风的 出现。对此, 要坚决抵制以减缓其对农村传统文化的冲 击。最后，充实闲暇生活。在村民的闲暇之时，多开展 一些公共文化活动，提高村民的生活品质，促进村民之 间的相互交流。

\section{5. 贴近村民的现实需求}

照搬城市模板, 并不能解决问题，反而还会破坏乡 村原有特色。建设乡村公共文化空间需要以村民的需求 为中心，参考村民的意见。首先，在建设公共文化空间 前, 广泛开展调研活动。知道群众的需求是什么, 进而 引导村民走出家门, 主动参与公共文化活动。其次, 在 进行基础设施建设过程中综合考虑距离、效用等多方因 素。在实践中，有一些农村社区在村委会修建文化活动 中心，但没有考虑村民的实际距离的远近，距离远的村 民不愿意去，从而造成设备的闲置和资源的浪费。最后， 从乡村特色文化入手，拒绝僵硬的城市模式。篮球场、 健身中心并不一定是村民最需要的, 村民们真正需要的 是最具实用性的、有吸引力的公共文化空间。

\section{7. 结语}

目前，乡村公共文化空间的公共性困境已经影响了 乡村文化的建设, 阻碍了乡村社会的全面振兴。一味的 进行改造和新建并不是缓解公共性危机的最佳对策，乡 村公共文化空间的建设要因地制宜，考虑各村实际情 况，照顾村民的现实需求。总的来说，当下乡村公共文 化建设要以人为本，培养村民的情感认同，帮助村民树 立正确的价值观, 从而振兴乡村文化, 振兴乡村。 


\section{REFERENCES}

[1]Chunfeng Gao.(2019)The Construction Path of Rural Public Cultural Space from the Perspective of Narrative Expression.Tribune of Study,(02)59-65.

[2]Chen Bo,Ting ting Li.(2015)Our National Rural Public Culture Space Rebuilding in Urbanization Acceleration Period:Theory and Mode Construction.Hundred Schools in Arts, (06):64-71+112.

[3]Zhang Lin,Binyi Liu,Qiuyi Song.(2016)Research on the Public Culture Space Planning of Modern Rural Communities_-Taking Yujiabian Village,Jurong City,Jiangsu Province as an Example.Journal of Chinese Urban Forestry, 14(03):12-16.

[4]Yongqiang Ma.(2011)The Significance and Realization of Rebuilding Rural Public Culture Space.Gansu Social Sciences, (03):179-183.

[5]Zhang chen,Zuyun Liu.(2018)Lost and Reconstructed:Construction of Rural Public Space in Post-native Society.Study and Practice, (04):108-115.

[6]Zhang Chen,Zuyun Liu.(2019)The Public Dilemma Rural Public Space and Its Reconstruction.Journal of Huazhong Agriculture University(Social Sciences Edition), (02):1-7+163.

[7]National Bureau of Statistics.(2017)Main Data Bullentin of the Third National Agriculture Census(No.3).http://www.stats.gov.cn/tjsj.

[8] National Bureau of Statistics.(2014-2018)Statistical Bulletin of National Economic and Social Development. http://www.stats.gov.cn/tjsj. 